\title{
Synaptic Vesicle Exocytosis
}

\author{
Thomas C. Südhof ${ }^{1}$ and Josep Rizo ${ }^{2}$ \\ ${ }^{1}$ Department of Molecular and Cellular Physiology, and Howard Hughes Medical Institute, Stanford \\ University Medical School, Stanford, California 94305 \\ ${ }^{2}$ Departments of Biochemistry and Pharmacology, University of Texas Southwestern Medical Center, \\ Dallas, Texas 75390 \\ Correspondence: tcs1@stanford.edu
}

Presynaptic nerve terminals release neurotransmitters by synaptic vesicle exocytosis. Membrane fusion mediating synaptic exocytosis and other intracellular membrane traffic is affected by a universal machinery that includes SNARE (for "soluble NSF-attachment protein receptor") and SM (for "Sec1/Munc18-like") proteins. During fusion, vesicular and target SNARE proteins assemble into an $\alpha$-helical trans-SNARE complex that forces the two membranes tightly together, and SM proteins likely wrap around assembling transSNARE complexes to catalyze membrane fusion. After fusion, SNARE complexes are dissociated by the ATPase NSF (for "N-ethylmaleimide sensitive factor"). Fusion-competent conformations of SNARE proteins are maintained by chaperone complexes composed of $\operatorname{CSP} \alpha, \mathrm{Hsc} 70$, and SGT, and by nonenzymatically acting synuclein chaperones; dysfunction of these chaperones results in neurodegeneration. The synaptic membrane-fusion machinery is controlled by synaptotagmin, and additionally regulated by a presynaptic protein matrix (the "active zone") that includes Munc13 and RIM proteins as central components.

$\mathbf{S}_{\text {ynaptic vesicles are uniform organelles of }}$ S 40 nm diameter that constitute the central organelle for neurotransmitter release. Each presynaptic nerve terminal contains hundreds of synaptic vesicles that are filled with neurotransmitters. When an action potential depolarizes the presynaptic plasma membrane, $\mathrm{Ca}^{2+}$-channels open, and $\mathrm{Ca}^{2+}$ flows into the nerve terminal to trigger the exocytosis of synaptic vesicles, thereby releasing their neurotransmitters into the synaptic cleft (Fig. 1). $\mathrm{Ca}^{2+}$ triggers exocytosis by binding to synaptotagmin; after exocytosis, vesicles are re-endocytosed, recycled, and refilled with neurotransmitters. Recycling can occur by multiple parallel pathways, either by fast recycling via local reuse of vesicles ("kiss-and-run" and "kiss-and-stay"), or by slower recycling via an endosomal intermediate (Fig. 1).

Due to their small size, synaptic vesicles contain a limited complement of proteins that have been described in detail (Südhof 2004; Takamori et al. 2006). Although the functions of several vesicle components remain to be identified, most vesicle components participate in one of three processes: neurotransmitter

Editors: Morgan Sheng, Bernardo Sabatini, and Thomas C. Südhof

Additional Perspectives on The Synapse available at www.cshperspectives.org

Copyright (C) 2011 Cold Spring Harbor Laboratory Press; all rights reserved; doi: 10.1101/cshperspect.a005637

Cite this article as Cold Spring Harb Perspect Biol 2011;3:a005637 
T.C. Südhof and J. Rizo

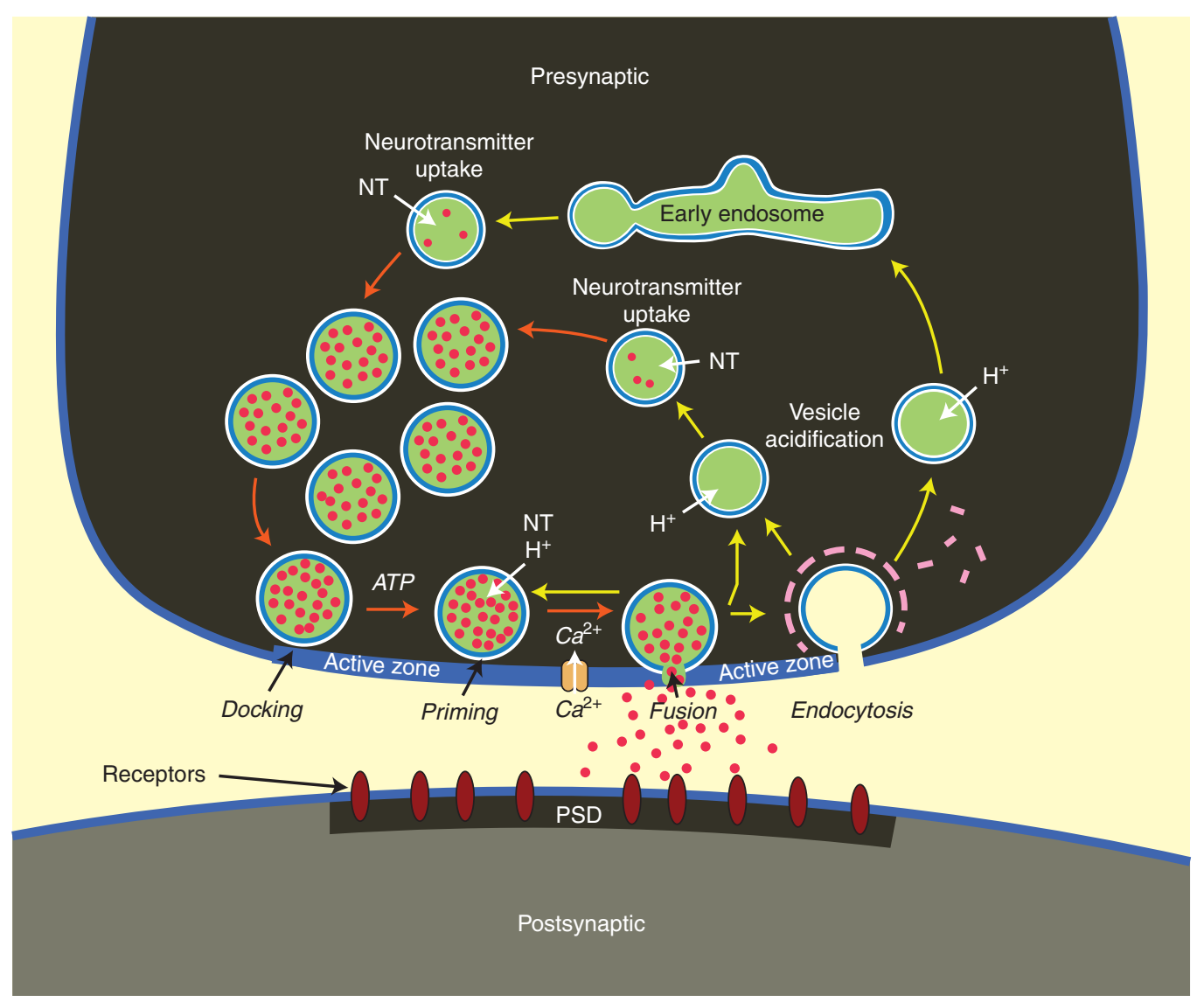

Figure 1. The synaptic vesicle cycle. A presynaptic nerve terminal is depicted schematically as it contacts a postsynaptic neuron. The synaptic vesicle cycle consists of exocytosis (red arrows) followed by endocytosis and recycling (yellow arrows). Synaptic vesicles (green circles) are filled with neurotransmitters (NT; red dots) by active transport (neurotransmitter uptake) fueled by an electrochemical gradient established by a proton pump that acidifies the vesicle interior (vesicle acidification; green background). In preparation to synaptic exocytosis, synaptic vesicles are docked at the active zone, and primed by an ATP-dependent process that renders the vesicles competent to respond to a $\mathrm{Ca}^{2+}$-signal. When an action potential depolarizes the presynaptic membrane, $\mathrm{Ca}^{2+}$ channels open, causing a local increase in intracellular $\mathrm{Ca}^{2+}$ at the active zone that triggers completion of the fusion reaction. Released neurotransmitters then bind to receptors associated with the postsynaptic density (PSD). After fusion pore opening, synaptic vesicles probably recycle via three alternative pathways: local refilling with neurotransmitters without undocking ("kiss-and-stay"), local recycling with undocking ("kiss-and-run"), and full recycling of vesicles with passage through an endosomal intermediate. (Adapted from Südhof 2004.)

uptake and storage, vesicle exocytosis, and vesicle endocytosis and recycling. In addition, it is likely that at least some vesicle proteins are involved in the biogenesis of synaptic vesicles and the maintenance of their exquisite uniformity and stability, but little is known about how vesicles are made, and what determines their size.

\section{SNARE PROTEINS MEDIATE SYNAPTIC VESICLE FUSION}

Membrane fusion is a universal process in eukaryotic cells - the formation and fusion of membranous organelles forms the basis of all of life's processes, from the compartmental organization of the most archaic cells to the 
sophistication of events such as synaptic transmission, fertilization, and immunity. The first clue to which molecules mediate membrane fusion was obtained at the synapse when SNARE proteins were identified as targets of clostridial botulinum and tetanus toxins. These powerful neurotoxins enter a presynaptic terminal and act as highly specific proteases that selectively block presynaptic membrane fusion without altering the morphological structure of the terminal. In 1992, the vesicular SNAREprotein synaptobrevin/VAMP (for "vesicleassociated membrane protein")—-whose designation as a "SNARE protein" occurred only later-was identified as the first essential fusion protein when it was shown that tetanus toxin and some botulinum toxin subtypes specifically cleave it in half (Link et al. 1992; Schiavo et al. 1992). Rapidly afterward, SNAP-25 and syntaxin-1 were shown to be substrates for different botulinum toxin subtypes, with several toxins often cleaving the same protein, but at different positions (Blasi et al. 1993a,b). These results provided the first evidence that these three proteins are essential components of the membrane fusion machinery, and suggested an immediate explanation for the finding that Caenorhabditis elegans homologs of these proteins were essential for nervous system function (Brenner 1974), and that yeast homologs of these proteins were required for membrane traffic in the secretory pathway (Novick et al. 1980).

Prior to the work on clostridial neurotoxins, in vitro fusion assays in a cell-free transport system had isolated NSF (for N-ethylmaleimide sensitive factor) as an essential factor for in vitro membrane traffic, and had shown that NSF acts via adaptor proteins called "SNAPs" (for "soluble NSF-attachment proteins," no relation to SNAP-25 and its homologs; Wilson et al. 1989). Immediately after the neurotoxin data identified synaptobrevin, SNAP-25, and syntaxin as essential for fusion, Rothman and colleagues discovered that these three proteins form a complex with each other that is dissociated by NSF, which acts as an ATPase (Söllner et al. 1993), leading to the "SNARE" ( for "soluble NSF-attachment protein receptor") designation. These findings led to the hypothesis that trans-SNARE complexes bridging the vesicle and plasma membranes mediate vesicle docking and targeting specificity, and that by analogy other SNAREs discovered by genetic screens in yeast and C. elegans as essential for membrane traffic might function similarly. Subsequently, SNARE complexes were found to be resistant to SDS, revealing their high stability (Hayashi et al. 1994), and to involve a parallel arrangement of helical regions of synaptobrevin and syntaxin-1 adjacent to their transmembrane regions (Hanson et al. 1997). At the same time, NSF was shown to act upstream of fusion and not in fusion as originally thought (Mayer et al. 1996). Together, these findings led to the notion that SNARE-complex assembly releases the energy that fuels membrane fusion by forcing membranes together. Consistent with this notion, the three-dimensional structure of the synaptic SNARE complex revealed that it forms a parallel four-helix bundle (Poirier et al. 1998; Sutton et al. 1998). After much additional work (reviewed in Jahn et al. 2003), all SNARE complexes are now believed to assemble similarly, and to mediate intracellular fusion by the same overall mechanism, although without their SM protein partners, SNARE-proteins are unable to effect fusion under physiological conditions (see below). The function of SNARE-proteins in fusion has been referred to as the "SNARE hypothesis," a term that has been applied with very different meanings over the years, and may be somewhat outdated because at least in our view the role of SNARE proteins in fusion is no longer a hypothesis.

SNARE proteins function in fusion by a cycle of assembly into complexes that fuel fusion, and disassembly of the complexes by NSF and SNAPs that makes SNARE proteins available again for another round of fusion (Figs. 2 and 3). The SNARE cycle starts with the amino- to carboxy-terminal zippering of trans-SNARE complexes that bridge the gap between the membranes destined to fuse. Full zippering of trans-SNARE complexes likely produces fusion-pore opening, although it is possible that the full zippering only stresses the membranes and that fusion-pore opening 
T.C. Südhof and J. Rizo

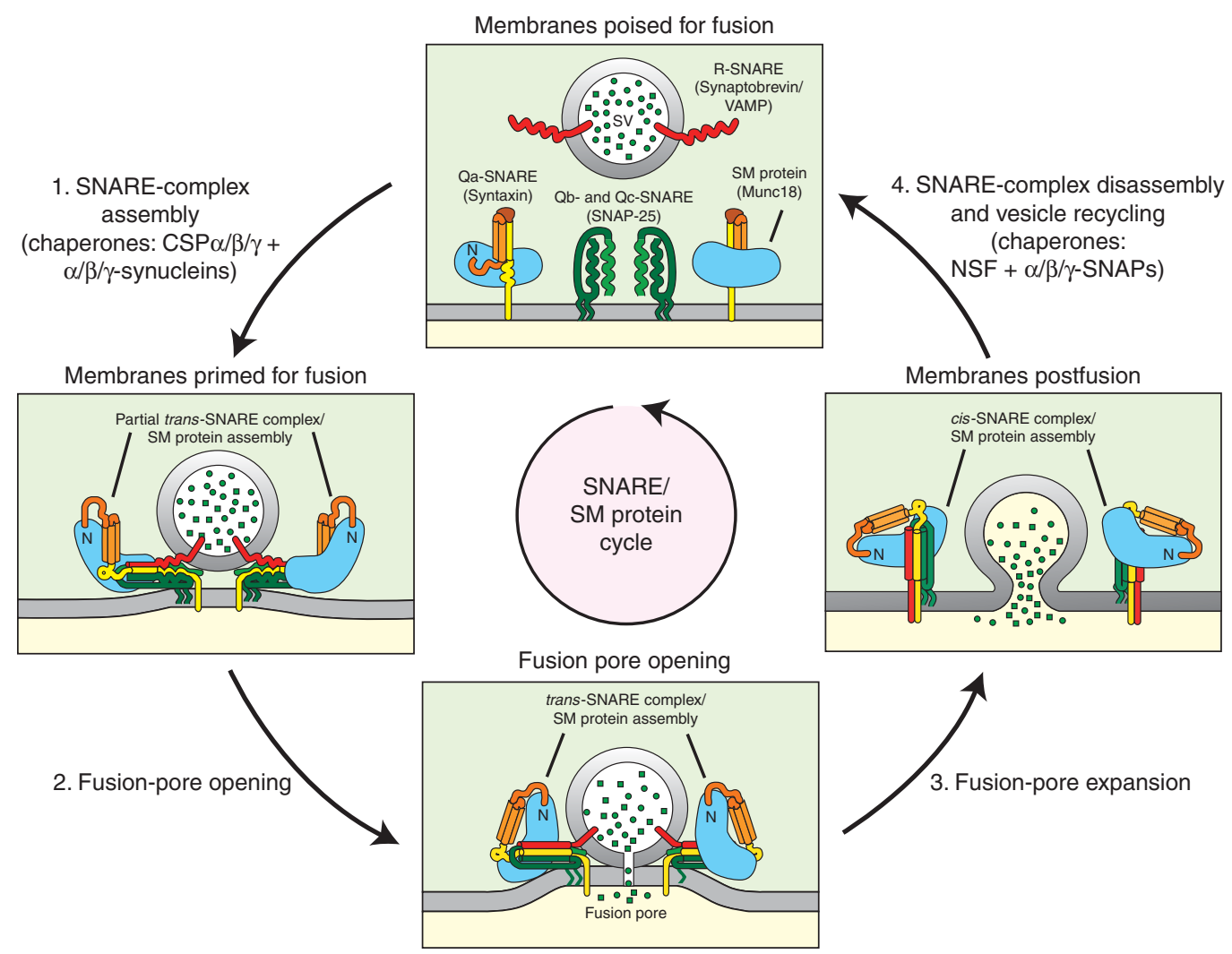

Figure 2. The SNARE/SM protein cycle. The diagram on top depicts SNARE and SM proteins prior to fusion, when they are localized to the membranes either as natively unfolded proteins (e.g., the R-SNARE synaptobrevin/VAMP) or as proteins folded in complexes distinct from canonical SNARE complexes (e.g., binding of the SM protein Munc18-1 to the closed conformation of syntaxin-1 as shown here, or as syntaxin-1/SNAP-25 heterodimeric complexes). During priming, SNARE proteins partially zipper up into trans-complexes, and the SM protein associates with the trans-complexes by binding to the syntaxin amino terminus (left diagram). Full SNARE-complex assembly then pulls the membranes apart, opening the fusion pore (bottom diagram), which expands such that the vesicle membrane collapses into the target membrane, and the trans-SNARE complexes are converted into cis-SNARE complexes (right diagram). Afterward, cis-SNARE complexes are dissociated by the ATPase NSF acting in conjunction with its adaptors $\alpha / \beta / \gamma$-SNAPs (no relation to SNAP-25 and its homologs_-an unfortunate coincidence of acronyms), and vesicles recycle to start another round of the cycle.

occurs subsequently mediated by the SM protein (see below). After fusion pore opening, the two membranes completely merge, and trans-SNARE complexes are converted into cis-SNARE complexes (i.e., SNARE complexes are on a single membrane), which are dissociated into monomers by NSF and SNAPs (Fig. 2). It is likely that NSF also acts on transSNARE complexes; moreover, SNARE proteins also associate in vitro into other complexes that are composed of different stoichiometries of only two proteins (e.g., syntaxin-SNAP-25 heterodimers) and may also be substrates for NSF. Independent of these other actions of NSF, however, fusion is driven overall by a cycle of SNARE association and dissociation. In this cycle, NSF “loads" SNARE proteins with energy by the ATP-dependent dissociation of SNARE complexes into reactive monomeric SNARE proteins; the energy of reactive SNARE proteins is then transformed into fusion via SNARE complex assembly. 

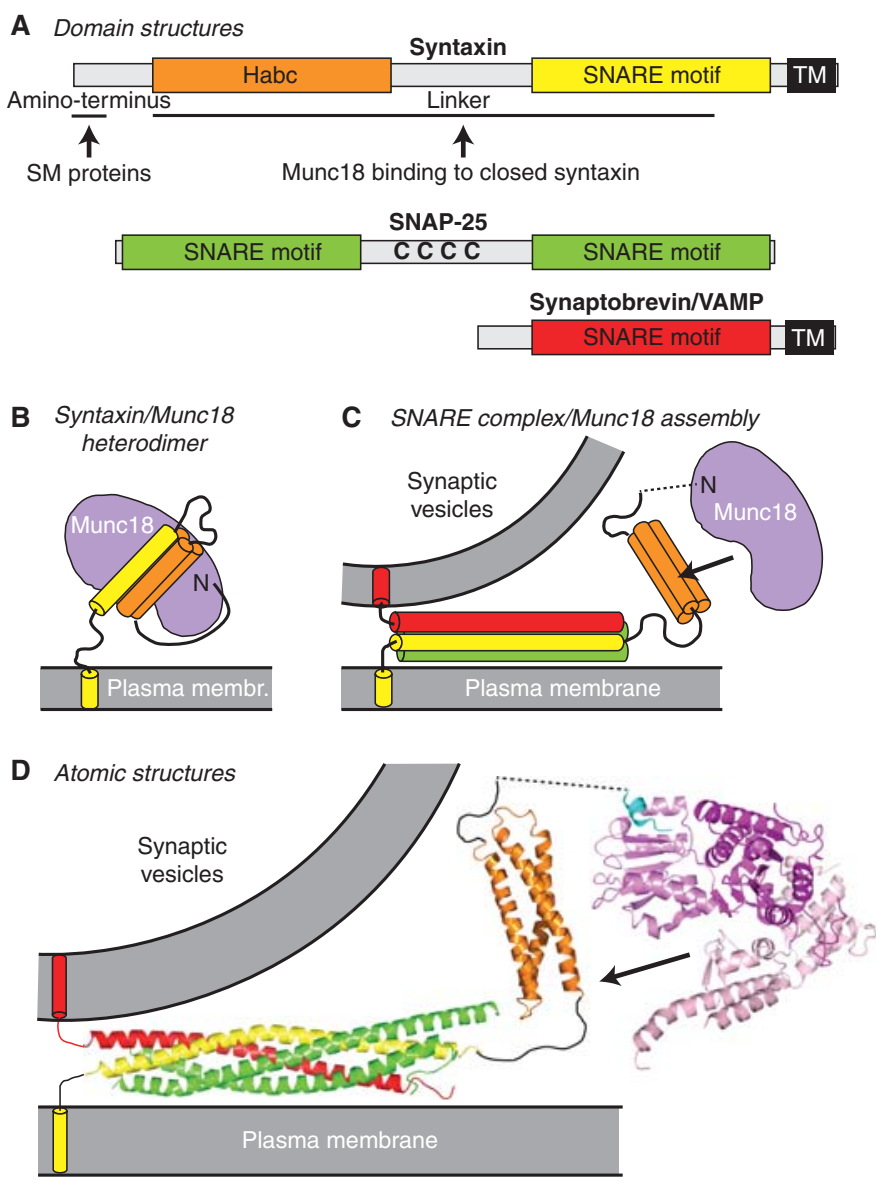

Figure 3. Structures of synaptic SNARE and SM proteins. (A) Schematic diagram of the domain structures of syntaxin, SNAP-25, and synaptobrevin/VAMP (Habc, Habc-domain; TM, transmembrane region). ( $B, C$ ) Cartoon of the two modes of interaction of the SM protein Munc18 with SNARE proteins during synaptic exocytosis: Binding of Munc18 to the closed conformation of syntaxin-1 that occludes the SNARE motif $(B)$, and binding of Munc18 to assembling SNARE trans-complexes that depends on the syntaxin-1 amino terminus $(C)$. Note that the precise mode of Munc18 binding to assembling SNARE complexes is unknown, apart from the fact that it is anchored by interaction of the syntaxin amino terminus (indicated by an $\mathrm{N}$ ) with the $\mathrm{N}$-lobe of Munc18; the arrow indicates the uncertain atomic nature of this binding, which may involve wrapping of Munc18 around the SNARE helical bundle analogous to the binding of Munc18 to the closed conformation of syntaxin (Südhof and Rothman 2009). (i) Atomic structures of the fully assembled SNARE complex, the synaxin-1A Habc domain, and Munc18 containing a bound syntaxin amino-terminal peptide (blue), drawn to scale. (Data for structures are from Sutton et al. 1998, Fernandez et al. 1998, and Hu et al. 2011, respectively.) Arrow indicates uncertainty in how precisely Munc18 binds to SNARE complexes apart from the interaction of the syntaxin amino terminus with the Munc18 N-lobe.

\section{SPECIFICITY OF SNARE-PROTEIN COMPLEX ASSEMBLY}

SNARE-proteins contain a characteristic sequence, referred to as the SNARE motif (Fig. $3 \mathrm{~A})$, that comprises $60-70$ residues composed of eight heptad repeats. Most SNARE proteins contain one SNARE motif, whereas SNAP-25 and its homologs (SNAP-23, -29, and -47) include two SNARE motifs. The four SNARE motifs of synaptic SNARE proteins assemble into the four-helix coiled coil structure of the 
SNARE complex (Fig. 3C,D) (Poirier et al. 1998; Sutton et al. 1998), with one SNARE motif each from synaptobrevin and syntaxin-1, and two SNARE motifs from SNAP-25. Among synaptic SNARE proteins, synaptobrevin is the simplest as it is only composed of a short amino-terminal sequence, a SNARE motif, and a carboxy-terminal membrane anchor (Fig. 3A). SNAP-25 is unique in containing two SNARE motifs but otherwise includes only a linker sequence that serves for membrane-anchoring via palmitoylation. Syntaxin-1 and its homologs, in contrast, are rather complex molecules that contain a conserved nonstructured amino-terminal sequence followed by an autonomously folded amino-terminal Habc-domain (Fernandez et al. 1998), a SNARE motif, and a transmembrane anchor (Fig. 2A). Of these sequences, the SNARE motif and transmembrane region only account for a third of the entire protein, which is thus largely composed of "non-SNARE" sequences. As we will see below, the interesting architecture of syntaxin-1 reflects a richer function in fusion, illustrating the fact that the function of SNARE proteins is not limited to assembly into SNARE complexes.

The four-helix bundle of a SNARE complex is formed primarily by hydrophobic interactions. All SNARE complexes, however, contain a conserved central hydrophilic layer of interacting amino acids that is composed of three glutamine and one arginine residue (Fasshauer et al. 1998). Sequence analyses suggested that SNARE motifs can be classified into four groups that are referred to as Qa-, Qb-, Qc-, and R-SNAREs based on this central layer residue. All physiological SNARE complexes are composed of one of each of the four SNARE groups, but otherwise SNARE-complex assembly is rather promiscuous (Fasshauer et al. 1999; Yang et al. 1999). Often, an R-SNARE is localized to a transport vesicle that then fuses with an acceptor membrane containing all three Q-SNAREs, in which case the R-SNARE is also called a v-SNARE (for "vesicular SNARE," although not all v-SNAREs act on vesicles) and the three Q-SNAREs are referred to as t-SNAREs (for "target-membrane SNARE”).
During fusion, SNARE proteins initially assemble into trans-complexes in an amino- to carboxy-terminal direction (Fig. 3). How assembly is nucleated remains unclear, although it appears likely that SM proteins contribute to the assembly initiation. SNARE-complex assembly is a highly exergonic process. Current evidence suggests that SNARE-complex formation promotes membrane fusion by simple mechanical force. The energy released during SNAREcomplex assembly likely fuels membrane fusion, i.e., provides the power that overcomes the energy barriers to membrane fusion-in that sense, SNARE proteins are truly the fusion motors.

Although much is understood about membrane fusion at the synapse and elsewhere, many major issues remain unresolved. For example, how does the specificity of SNARE-complex assembly arise, given the fact that such assembly is promiscuous in vitro, and that many organelles, including synaptic vesicles, contain multiple SNARE proteins that participate in selective but distinct fusion reactions of the same organelle (e.g., exocytosis vs. endosome fusion of synaptic vesicles)? Why is there a topological restriction in fusion in that the R-SNARE synaptobrevin on synaptic vesicles acts in conjunction with plasma membrane Q-SNAREs during synaptic exocytosis, even though the Q-SNARES are actually present on synaptic vesicles as well (Otto et al. 1997)?

\section{SM PROTEINS}

SM proteins are essential partners for SNARE proteins in fusion-without one or the other, no fusion occurs physiologically. SM proteins are evolutionarily conserved cytosolic proteins of approximately 600 residues that are composed of three lobes folding into an arch-shaped "clasp" structure (Fig. 3D). Despite the fact that an essential role for SM proteins in fusion was suggested in initial studies of Munc18-1 in synaptic exocytosis immediately following the discovery of the function of SNARE proteins (Hata et al. 1993), the importance of SM proteins was questioned for more than a decade.

Two circumstances contributed to the uncertainty of SM protein function. First, SNARE 
proteins can induce fusion of liposomes without SM proteins (Weber et al. 1998; van den Bogaart et al. 2010), and second, the biochemistry of the SNARE/SM protein interaction was initially difficult to fit into a simple model (Dulubova et al. 1999). The first circumstance was more intuitive than rational, because many proteins including bovine-serum albumin are known to promote liposome fusion; hence, in liposome fusion studies it is critical to show that fusion shows similar requirements to those observed physiologically before functional conclusions can be drawn.

The second circumstance, however, posed a genuine conceptual challenge. Initial studies suggested that SM proteins interact with SNARE proteins not by a uniform mechanism, but in diverse and occasionally incompatible ways. Specifically, Munc18 was shown to bind to the closed conformation of syntaxin-1 (Fig. 3B) (Dulubova et al. 1999). This binding appeared to prevent syntaxin-1 from engaging into SNARE complexes, and led to the suggestion that Munc18 is an inhibitor of fusion instead of a component of the fusion machine (Wu et al. 2001), despite the fact that deletion of Munc18 caused a loss of fusion instead of increased fusion (Verhage et al. 2000). Moreover, the Munc18 homolog in yeast, Seclp, was shown to bind only to assembled SNARE complexes (Carr et al. 1999), creating an additional interpretational dilemma.

This puzzle was only resolved, at least as regards mammalian fusion, when it was shown that a conserved sequence at the amino terminus of syntaxins binds SM proteins by a novel mechanism that is compatible with full SNAREcomplex assembly (Fig. 3C). Initially described for SNARE and SM proteins involved in endoplasmic reticulum, Golgi, and endosome traffic (Dulubova et al. 2002; Yamaguchi et al. 2002), this mechanism was extended to the corresponding proteins involved in exocytosis (Dulubova et al. 2007; Khvotchev et al. 2007; Shen et al. 2007). As a result, a unified view of SM/SNARE protein interactions emerged that appears to apply to most intracellular fusion reactions, whereby SM proteins are attached to assembling SNARE complexes via short peptide sequences, usually localized to syntaxin, which allows the SM proteins to hang onto the assembling SNARE complexes independent of the conformation of the SNARE motif (Fig. 2). The amino-terminal peptide on syntaxin-1 that tethers the SM protein Munc18 is absolutely essential for fusion in vivo, whereas the closed syntaxin conformation may be dispensable, at least for fusion as such (Khvotchev et al. 2007; Gerber et al. 2008; Rathore et al. 2010).

Despite these more recent results, the initial findings of Munc18-binding to the closed conformation of syntaxin did not turn out to be irrelevant. Knock-in mice in which syntaxin-1 carries a point mutation that renders it predominantly open, thereby decreasing Munc18-binding to the closed monomeric conformation of syntaxin-1 without altering Munc18-binding to syntaxin-1 containing SNARE complexes, show a dramatic synaptic transmission phenotype (Gerber et al. 2008). This phenotype included an increased release probability combined with a decreased number of synaptic vesicles available for release, suggesting that the Munc18 interaction with the Habc domain of syntaxin-1 in its closed conformation may regulate release, as opposed to the Munc18 interaction with the amino-terminal syntaxin-1 peptide that is essential for fusion as such. Thus, at present, the role of the syntaxin Habc domain and its binding of Munc18 are only incompletely understood.

\section{COOPERATION OF SNARE AND SM PROTEINS IN SYNAPTIC EXOCYTOSIS}

Why do SNARE proteins require SM proteins for fusion? Although no definitive answer to this question is available, the structure of SM proteins suggests that they may wrap around assembling SNARE complexes (Fig. 3D). This interaction may spatially organize SNARE complexes, keep them from sliding into the space between the fusing membranes and thereby block fusion, and promote SNARE complex assembly (Dulubova et al. 2007). Moreover, SM proteins may directly catalyze phospholipid mixing during fusion by interacting with the phospholipid membranes close to SNARE 
complexes, perhaps altering the membrane curvature (Carr and Rizo 2010). Some other hypotheses, however, appear to be rather unlikely. SM proteins probably do not confer specificity to fusion reactions because the same SM protein is often used in different fusion reactions, as are less frequently the same SNARE proteins. Specificity likely resides primarily in adaptor proteins, including Rab proteins and their effectors, which act on SNARE and SM proteins. Similarly, although SM proteins continue to be referred to as regulators, their primary function does not appear to be regulatory but executive because deletions of SM proteins block fusion, and because SM proteins are not widely regulated by classical signaling mechanisms, such as calcium, phosphorylation, or other second messengers. Testing these and additional hypotheses will be difficult until a better understanding of the biophysical chemistry of membrane fusion is available.

Conceptually, we differentiate in synaptic exocytosis between synaptic vesicle docking and fusion, with the latter probably starting during the priming of vesicles, and finishing during the $\mathrm{Ca}^{2+}$-triggering of fusion-pore opening by synaptotagmin (Figs. 1 and 2). Although SNARE and SM proteins are not essential for synaptic vesicle docking, defined as the attachment of vesicles to the active zone at the synapse, binding of Munc18 to the closed conformation of syntaxin-1 is essential for vesicle docking in chromaffin cell exocytosis (Gerber et al. 2008). Thus, SNARE and SM protein complexes may stabilize the attachment of vesicles to the target membrane and thereby participate in docking, consistent with the notion that SNARE and SM protein complexes assemble at least partly prior to exocytosis during vesicle priming.

\section{$\mathrm{CSP} \alpha$ AND SYNUCLEINS - SNARE CHAPERONES PREVENTING NEURODEGENERATION}

At a synapse, every release event is associated with assembly of SNARE complexes and their disassembly by NSF and SNAPs. At any given time, a presynaptic terminal likely contains hundreds of unfolded or partly folded SNARE protein molecules, carrying exposed reactive SNARE motifs that are prone to nonspecific interactions and/or misfolding. It is thus not surprising that neurons in particular, and all cells in general, developed at least two chaperone systems to maintain functional SNARE conformations and promote SNARE-complex assembly (Fig. 4). Both of these chaperonesa complex composed of $\operatorname{CSP} \alpha$ (for "cysteine string protein $\alpha$ ”), Hsc70, and SGT (for "glutamate- and threonine-rich protein"; Tobaben et al. 2001) and the synucleins (Burré et al. 2010)_are linked to neurodegeneration, suggesting that abnormal exposure of neurons to misfolded SNAREs and/or abnormal SNARE-complex assembly may impair neuronal survival.

$\mathrm{CSP} \alpha$ is an evolutionarily conserved synaptic vesicle protein containing a DNA-J domain typical for cochaperones. When complexed with the DNA-K-domain protein Hsc70 and the tetrotricopeptide repeat protein SGT (Fig. 4), $\operatorname{CSP} \alpha$ mediates the ATP-dependent refolding of denatured luciferase as a model substrate (Tobaben et al. 2001) and prevents in an ATP-dependent manner the aggregation of SNAP-25 (Sharma et al. 2011). Deletion of $\operatorname{CSP} \alpha$ in mice has no immediate effects on neurotransmitter release, but leads to increased ubiquitination and degradation of SNAP-25 and to decreased SNARE-complex assembly, resulting in fulminant neurodegeneration that kills the mice after 2-3 mo (Fernandez-Chacon et al. 2004; Sharma et al. 2011).

Synucleins comprise a family of three proteins $(\alpha-, \beta-$, and $\gamma$-synuclein) that attracted attention because $\alpha$-synuclein mutations or overexpression lead to Parkinson's disease in human patients, and because many neurodegenerative disorders feature inclusions called Lewy bodies that contain $\alpha$-synuclein (Galvin et al. 2001). Synucleins are small proteins that bind to negatively charged phospholipids as $\alpha$-helices. Different from $\operatorname{CSP} \alpha$, synucleins are only observed in vertebrates. A role for synucleins in SNARE-complex assembly emerged from the surprising finding that moderate 


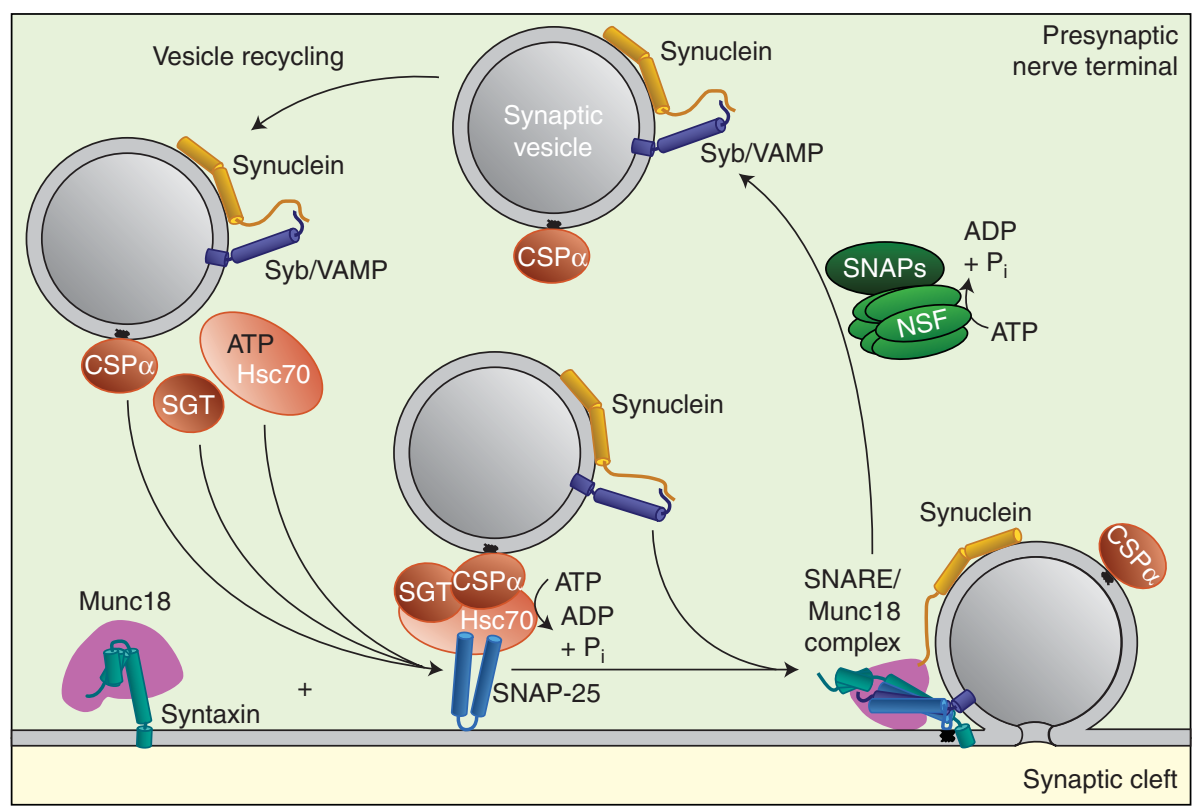

Figure 4. Two types of chaperones support SNARE protein function. Synaptic SNARE proteins are subject to continuous folding and unfolding reactions, creating the potential for misfolding that is counteracted by at least two SNARE chaperones implicated in neurodegeneration: the classical chaperone complex containing CSP $\alpha$ (for cysteine-string protein $\alpha$ ), Hsc70, and SGT (red shapes), and the nonclassical chaperones $\alpha / \beta /$ $\gamma$-synucleins (yellow shapes). CSP $\alpha$ and synucleins are vesicle proteins that act by distinct mechanisms. CSP $\alpha$ forms a complex with Hsc70 and SGT on the vesicle that binds to SNAP-25 on the target membrane and supports the functional competence of SNAP-25 to engage in SNARE complexes, whereas synucleins are bound to phospholipids and synaptobrevin (Syb)/VAMP on the vesicles, and bind to assembling SNARE complexes to support their folding.

overexpression of $\alpha$-synuclein completely rescues the lethal neurodegeneration produced by the knockout of CSP $\alpha$ (Chandra et al. 2005). Biochemically, $\alpha$-synuclein rescued the SNARE-complex assembly deficit in $\operatorname{CSP} \alpha$ knockout mice, but not their loss of SNAP-25. Subsequent studies uncovered a direct enhancement of SNARE-complex assembly by $\alpha$ synuclein in a purified reconstituted system containing only recombinant SNARE poteins and $\alpha$-synuclein (Burré et al. 2010). Moreover, deletion of all synuclein isoforms, although not lethal, leads to destabilization of SNARE complexes in vivo, and to an age-dependent neurological phenotype that increasingly incapacitates mice after 1 year of age (Burré et al. 2010).

Because $\alpha$-synuclein normally functions to promote SNARE-complex assembly, how does overexpression of $\alpha$-synuclein in patients carrying duplication or triplication of the $\alpha$ synuclein gene cause neurodegeneration (Eriksen et al. 2005)? At present, two alternative hypotheses are plausible. First, an increase in SNARE chaperoning may be detrimental, possibly by upsetting the balance of fusion in nerve terminals; second, misfolding of $\alpha$-synuclein-which is a reactive protein due to its function-may produce toxic conformers that cause neuronal damage. The second hypothesis appears more likely because only $\alpha$-synuclein but not $\beta$ - or $\gamma$-synuclein mutations have been identified in Parkinson's disease. If the normal function of $\alpha$-synuclein was involved in its pathogenic action, one would expect the other synucleins, which likely have similar functions, to be also pathogenic. However, until the mechanism of synuclein toxicity is uncovered, 
T.C. Südhof and J. Rizo

both hypotheses, and probably others as well, are conceivable.

\section{EMBEDDING THE SNARE/SM PROTEIN FUSION MACHINERY IN THE ACTIVE ZONE}

During synaptic exocytosis, synaptic vesicles dock and fuse at the presynaptic active zone, an electron-dense proteinaceous structure. Active zones contain at least four key protein components (Fig. 5): Munc13's (no relation to Munc18's; Brose et al. 1995), RIMs (for Rab3-interacting molecules; Wang et al. 1997), RIM-BPs (for RIM-binding proteins; Wang et al. 2000), and $\alpha$-liprins (Zhen and Jin 1999). In addition, piccolo/bassoon (a family of large cytomatrix proteins; piccolo is also called aczonin; tom Dieck et al. 1998; Wang et al. 1999; Fenster et al. 2000) and ELKS (also known as Rab6-interacting protein, CAST, or ERC; Ohtsuka et al. 2002; Wang et al. 2002) are genuine active zone proteins. Finally, adaptor proteins such as CASK, Velis, and Mints as well as endocytic scaffolding proteins such as intersectin, syndapin, amphiphysin, and others are probably peripherally associated with the active zone. It is likely that additional obligatory active zone proteins exist that have not yet been identified; for example, a scaffolding protein called Syd-1 is an essential presynaptic protein in C. elegans (Hallam et al. 2002), but no true vertebrate homolog has been described. These standard active zone proteins are present in all types of synapses, not only classical excitatory and inhibitory central synapses but also in neuromuscular junctions and ribbon synapses. The

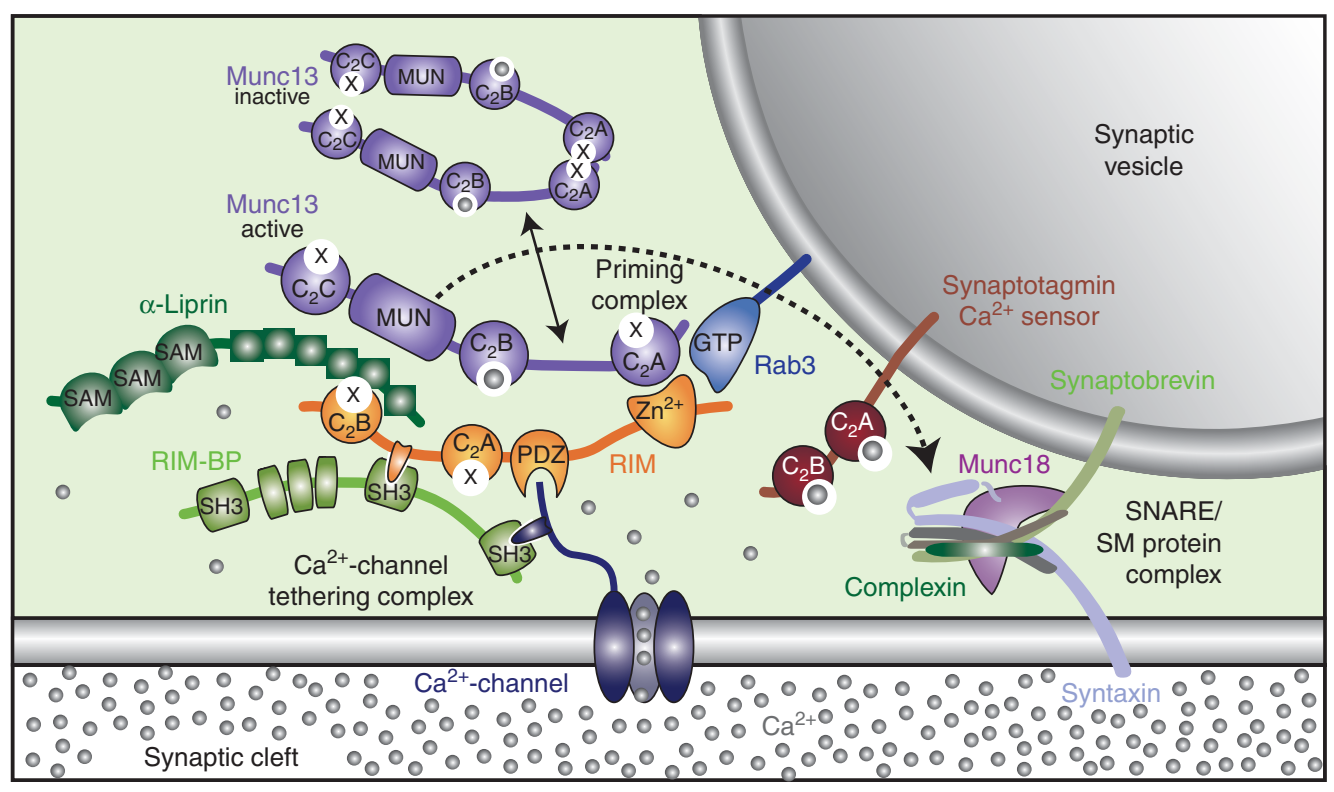

Figure 5. Model of active zone protein function. A complex composed of four out of the six canonical components of active zones (Munc13, $\alpha$-liprins, RIMs, and RIM-BPs) is shown; the remaining two canonical active zone proteins (ELKS and Piccolo/Bassoon) bind peripherally to the complex, and are not shown. The active zone complex is formed by an interaction of the amino-terminal zinc-finger domain of RIM with the aminoterminal C2A-domain of Munc13; by an interaction of a proline-rich sequence in RIM with a RIM-BP SH3-domain, and by a binding of $\alpha$-liprins to the RIM C2B-domain. The complex is anchored on synaptic vesicles via RIM binding to Rab3 and possibly also via RIM binding synaptotagmin (not shown), and on the plasma membrane via direct binding of RIM and of RIM-BP to N- and P/Q-type $\mathrm{Ca}^{2+}$-channels. Note that there are likely additional interactions among the various active zone proteins, and between these proteins and the presynaptic plasma membrane. $\mathrm{Ca}^{2+}$-ions are shown as dots; most of the active zone proteins contain $\mathrm{C} 2$-domains similar to synaptotagmin, but only a subset of the $\mathrm{C} 2$-domains bind $\mathrm{Ca}^{2+}$. 
latter, however, contain an additional special protein component called Ribeye that is evolutionarily derived from the fusion of the transcription factor CtBP2 with a novel aminoterminal Ribeye-specific domain (Schmitz et al. 2000).

Active zones mediate at least three broad, overlapping functions of presynaptic terminals: (1) They physically link synaptic vesicles, calcium channels, and other presynaptic components into a single complex, thereby ensuring efficient colocalization of the elements that only enables fast synaptic transmission; (2) They organize presynaptic receptors to allow presynaptic modulation of neurotransmitter release, for example by endocannabinoids or by autoreceptors; and (3) They mediate various forms of short- and long-term presynaptic plasticity. All of these three functions are crucial for synaptic transmission.

Munc13 and RIM proteins, currently the best understood active zone proteins, are multidomain proteins that are expressed in several isoforms transcribed from multiple promoters in multiple genes. The predominant Munc13 isoforms contain an amino-terminal C2Adomain that does not bind $\mathrm{Ca}^{2+}$, but forms a constitutive homodimer (Fig. 5). Munc13 also contains a central regulatory cassette composed of a calmodulin-binding sequence (Junge et al. 2004), a C1-domain that is regulated by diacylglycerol (Rhee et al. 2002), and a central C2B-domain that binds $\mathrm{Ca}^{2+}$ in a PIP2dependent manner (Shin et al. 2010). The carboxy-terminal half of Munc13 proteins is composed of its executive "MUN" domain and a carboxy-terminal C2C-domain that also does not bind $\mathrm{Ca}^{2+}$. Functionally, Munc13 is essential for synaptic vesicle priming (Augustin et al. 1999); its function is tightly regulated by $\mathrm{Ca}^{2+}$ (via the C2B-domain, diacylglycerol synthesis, and calmodulin) and RIM (see below). In priming, Munc13 probably acts via a direct or indirect interaction of the MUN-domain with SNARE and/or SM proteins (Ma et al. 2011).

The domain structure of RIM proteins is even more complex than that of Munc13's (Wang et al. 1997, 2000). $\alpha$-RIM proteins, the predominant isoforms, contain an amino-terminal sequence that includes two nested domains: two $\alpha$-helices that interact with the vesicle GTP-binding protein Rab3 (hence the name "RIM"), and that are separated by a zincfinger that binds to the Munc13 C2A-domain (Fig. 5) (Lu et al. 2006). Interestingly, RIM zinc-finger binding to the Munc13 C2Adomain competes with the homodimerization of the C2A-domain; because the former shows a higher affinity than the latter, the presence of the RIM zinc-finger converts the Munc13 C2Adomain homodimer into a RIM/Munc13 heterodimer ( $\mathrm{Lu}$ et al. 2006). RIMs contain a central PDZ-domain that binds to ELKS proteins and to $\mathrm{N}$ - and $\mathrm{P} / \mathrm{Q}$-type $\mathrm{Ca}^{2+}$-channels (Wang et al. 2000; Ohtsuka et al. 2002; Kaeser et al. 2011), and two carboxy-terminal C2-domains that do not bind $\mathrm{Ca}^{2+}$. The sequence between the two C2-domains includes a short prolinerich sequence that binds to RIM-BPs (RIMbinding proteins; Wang et al. 2000), whereas the second RIM C2-domain (the C2B-domain) binds to the active zone protein $\alpha$-liprin (Schoch et al. 2002). RIM proteins are thus central elements of active zones that interact with most other active zone proteins.

Functionally, RIM proteins perform at least two essential functions. First, RIM proteins regulate the priming activity of Munc13 (Deng et al. 2011). Deletions of RIM proteins produce a severe priming defect (Koushika et al. 2001; Schoch et al. 2002); strikingly, this defect can be partly reversed by expression of the RIM zinc-finger alone (Deng et al. 2011). The priming defect of RIM-deficient synapses is also compensated by expression of mutant Munc13 (but not a wild-type Munc13) either lacking the homodimerizing C2A-domain, or containing a point mutation in the $\mathrm{C} 2 \mathrm{~A}$-domain that blocks homodimerization (Deng et al. 2011). These data indicate that Munc13 homodimerization inhibits the priming function of Munc13, and that RIM activates Munc13 by converting the homodimer into a RIM/ Munc13 heterodimer.

Second, RIM proteins tether $\mathrm{Ca}^{2+}$-channels to the active zone. It was known for many years that $\mathrm{Ca}^{2+}$-channels are enriched at the site of 
neurotransmitter release, thereby allowing tight coupling of $\mathrm{Ca}^{2+}$-influx to triggering of fusion (Simon and Llinas 1985). However, only very recently the molecular mechanism recruiting $\mathrm{Ca}^{2+}$-channels to active zones was shown to depend on RIM proteins (Kaeser et al. 2011). Specifically, RIM proteins bind directly to the carboxyl terminus of $\mathrm{N}$ - and P/Q-type $\mathrm{Ca}^{2+}$ channels via their PDZ-domain, and indirectly to the cytoplasmic tails of the same $\mathrm{Ca}^{2+}$ channels via RIM-BP (Fig. 5). Deletion of RIM proteins from synapses leads to a selective loss of $\mathrm{Ca}^{2+}$-channels from presynaptic specializations, and a decrease in action-potential induced $\mathrm{Ca}^{2+}$-influx; this phenotype can only be rescued by RIM fragments containing both the PDZ-domain and the RIM-BP binding sequence (Kaeser et al. 2011). Thus, RIM proteins tether $\mathrm{Ca}^{2+}$-channels to active zones, connecting the channels to synaptic vesicles and to other active zone proteins via their various binding activities.

\section{CONCLUDING REMARKS}

As we described in this review, synaptic exocytosis is mediated by a hierarchically organized machinery that contains SNARE and SM proteins at its core, is maintained by NSF and SNAPs and by specific SNARE chaperones dedicated to its continuous operation, and is regulated by active zone proteins. In addition, the SNARE and SM fusion machine is controlled by $\mathrm{Ca}^{2+}$ via synaptotagmin and complexin.

\section{ACKNOWLEDGMENTS}

We are indebted to the NIH and the Howard Hughes Medical Institute for continuous support (grants supporting the work described here: MH086403, NS053862, and MH089054 to T.C.S., and NS37200 and NS40944 to J.R.).

\section{REFERENCES}

Augustin I, Rosenmund C, Südhof TC, Brose N. 1999. Munc-13 is essential for fusion competence of glutamatergic synaptic vesicles. Nature 400: 457-461.

Blasi J, Chapman ER, Link E, Binz T, Yamasaki S, De Camilli P, Südhof TC, Niemann H, Jahn R. 1993a. Botulinum neurotoxin A selectively cleaves the synaptic protein SNAP-25. Nature 365: 160-163.

Blasi J, Chapman ER, Yamasaki S, Binz T, Niemann H, Jahn R. 1993b. Botulinum neurotoxin C1 blocks neurotransmitter release by means of cleaving HPC-1/syntaxin. EMBO J 12: 4821-4828.

Brenner S. 1974. The genetics of Caenorhabditis elegans. Genetics 77: 71-94.

Brose N, Hofmann K, Hata Y, Südhof TC. 1995. Mammalian homologues of C. elegans unc-13 gene define novel family of C2-domain proteins. J Biol Chem 270: 25273-25280.

Burré J, Sharma M, Tsetsenis T, Buchman V, Etherton M, Südhof TC. 2010. $\alpha$-Synuclein promotes SNARE-complex assembly in vivo and in vitro. Science 329: 16641668.

Carr CM, Rizo J. 2010. At the junction of SNARE and SM protein function. Curr Opin Cell Biol 22: 488-495.

Carr CM, Grote E, Munson M, Hughson FM, Novick PJ. 1999. Seclp binds to SNARE complexes and concentrates at sites of secretion. J Cell Biol 146: 333-344.

Chandra S, Gallardo G, Fernández-Chacón R, Schlüter OM, Südhof TC. 2005. $\alpha$-Synuclein cooperates with CSP $\alpha$ in preventing neurodegeneration. Cell 123: 383-396.

Deng L, Kaeser PS, Xu W, Südhof TC. 2011. RIM proteins activate vesicle priming by reversing auto-inhibitory homodimerization of Munc13. Neuron 69: 317-331.

Dulubova I, Sugita S, Hill S, Hosaka M, Fernandez I, Südhof TC, Rizo J. 1999. A conformational switch in syntaxin during exocytosis. EMBO J 18: 4372-4382.

Dulubova I, Yamaguchi T, Min SW, Gao Y, Südhof TC, Rizo J. 2002. How Tlg2p/syntaxin 16 "snares” Vps45. EMBO J 21: $3620-3631$.

Dulubova I, Khvotchev M, Südhof TC, Rizo J. 2007. Munc18-1 binds directly to the neuronal SNARE complex. Proc Natl Acad Sci 104: 2697-2702.

Eriksen JL, Przedborski S, Petrucelli L. 2005. Gene dosage and pathogenesis of Parkinson's disease. Trends Mol Med 11: 91-96.

Fasshauer D, Sutton RB, Brunger AT, Jahn R. 1998. Conserved structural features of the synaptic fusion complex: SNARE proteins reclassified as Q- and R-SNAREs. Proc Natl Acad Sci 95: 15781-15786.

Fasshauer D, Antonin W, Margittai M, Pabst S, Jahn R. 1999. Mixed and non-cognate SNARE complexes. Characterization of assembly and biophysical properties. J Biol Chem 274: 15440-15446.

Fenster SD, Chung WJ, Zhai R, Cases-Langhoff C, Voss B, Garner AM, Kaempf U, Kindler S, Gundelfinger ED, Garner CC. 2000. Piccolo, a presynaptic zinc finger protein structurally related to bassoon. Neuron 25: 203-214.

Fernandez I, Ubach J, Dulubova I, Zhang X, Südhof TC, Rizo J. 1998. Three-dimensional structure of an evolutionarily conserved N-terminal domain of syntaxin 1A. Cell 94: $841-849$.

Fernández-Chacón RF, Wölfel M, Nishimune H, Tabares L, Schmitz F, Castellano-Muñoz M, Rosenmund C, Montesinos ML, Sanes JR, Schneggenburger R. 2004. The synaptic vesicle protein CSP prevents presynaptic degeneration. Neuron 42: 237-251. 
Galvin JE, Lee VM, Trojanowski JQ. 2001. Synucleinopathies: Clinical and pathological implications. Arch Neurol 58: $186-190$.

Gerber SH, Rah J-C, Min S-W, Liu X, de Wit H, Dulubova I, Meyer AC, Rizo J, Arancillo M, Hammer, et al. 2008. Conformational switch of syntaxin-1 controls synaptic vesicle fusion. Science 321: 1507-1510.

Hallam SJ, Goncharov A, McEwen J, Baran R, Jin Y. 2002. SYD-1, a presynaptic protein with PDZ, C2 and rhoGAPlike domains, specifies axon identity in C. elegans. Nat Neurosci 5: 1137-1146.

Hanson PI, Roth R, Morisaki H, Jahn R, Heuser JE. 1997. Structure and conformational changes in NSF and its membrane receptor complexes visualized by quickfreeze/deep-etch electron microscopy. Cell 90: 523-535.

Hata Y, Slaughter CA, Südhof TC. 1993. Synaptic vesicle fusion complex contains unc-18 homologue bound to syntaxin. Nature 366: 347-351.

Hayashi T, McMahon H, Yamasaki S, Binz T, Hata Y, Südhof TC, Niemann H. 1994. Synaptic vesicle membrane fusion complex: Action of clostridial neurotoxins on assembly. EMBO J 13: 5051-5061.

Hu SH, Christie MP, Saez NJ, Latham CF, Jarrott R, Lua LH, Collins BM, Martin JL. 2011. Possible roles for Munc181 domain 3a and Syntaxin1 N-peptide and C-terminal anchor in SNARE complex formation. Proc Natl Acad Sci 108: 1040-1045.

Jahn R, Lang T, Südhof TC. 2003. Membrane fusion. Cell 112: $519-533$.

Junge HJ, et al. 2004. Calmodulin and Munc13 form a $\mathrm{Ca}^{2+}$ sensor/effector complex that controls short-term synaptic plasticity. Cell 118: $389-401$.

Kaeser PS, Deng L, Wang Y, Dulubova I, Liu X, Rizo J, Südhof TC. 2011. RIM proteins tether $\mathrm{Ca}^{2+}$-channels to presynaptic active zones via a direct PDZ-domain interaction. Cell 144: 282-295.

Khvotchev M, Dulubova I, Sun J, Dai H, Rizo J, Südhof TC. 2007. Dual modes of Munc18-1/SNARE interactions are coupled by functionally critical binding to syntaxin- 1 N-terminus. J Neurosci 27: 12147-12155.

Koushika SP, Richmond JE, Hadwiger G, Weimer RM, Jorgensen EM, Nonet ML. 2001. A post-docking role for active zone protein Rim. Nat Neurosci 4: 997-1005.

Link E, Edelmann L, Chow JH, Binz T, Yamasaki S, Eisel U, Baumert M, Südhof TC, Niemann H, Jahn R. 1992. Tetanus toxin action: Inhibition of neurotransmitter release linked to synaptobrevin poteolysis. Biochem Biophys Res Commun 189: 1017-1023.

Lu J, Machius M, Dulubova I, Dai H, Südhof TC, Tomchick D, Rizo J. 2006. Structural Basis for a Munc13-1 Homodimer-Munc13-1/RIM Heterodimer Switch: C2-domains as versatile protein-protein interaction modules. PLOS Biol 4: e192.

Ma C, Li W, Xu Y, Rizo J. 2011. Munc13 mediates the transition from the syntaxin-Munc18 complex to the SNARE complex. Nat Struct Mol Biol 18: 542-549.

Mayer A, Wickner W, Haas A. 1996. Sec18p (NSF)-driven release of Sec17p ( $\alpha$-SNAP) can precede docking and fusion of yeast vacuoles. Cell 85: 83-94.
Novick P, Field C, Schekman R. 1980. Identification of 23 complementation groups required for post-translational events in the yeast secretory pathway. Cell 21: 205-215.

Ohtsuka T, Takao-Rikitsu E, Inoue E, Inoue M, Takeuchi M, Matsubara K, Deguchi-Tawarada M, Satoh K, Morimoto K, Nakanishi H Cast, et al. 2002. Cast: AAAA novel protein of the cytomatrix at the active zone of synapses that forms a ternary complex with RIM1 and munc13-1. J Cell Biol 158: 577-590.

Otto H, Hanson PI, Jahn R. 1997. Assembly and disassembly of a ternary complex of synaptobrevin, syntaxin, and SNAP-25 in the membrane of synaptic vesicles. Proc Natl Acad Sci 12: 6197-201.

Poirier MA, Xiao W, Macosko JC, Chan C, Shin YK, Bennett MK. 1998. The synaptic SNARE complex is a parallel four-stranded helical bundle. Nat Struct Biol 5: 765-769.

Rhee S-R, Betz A, Pyott S, Reim K, Varoqueaux F, Augustin I, Hesse D, Südhof TC, Takahashi M, Rosenmund C. 2002. Phorbol ester- and diacylglycerol-induced augmentation of neurotransmitter release from hippocampal neurons is mediated by Munc13s and not by PKCs. Cell 108: $121-133$.

Rathore SS, Bend EG, Yu H, Hammarlund M, Jorgensen EM, Shen J. 2010. Syntaxin N-terminal peptide motif is an initiation factor for the assembly of the SNARESec1/Munc18 membrane fusion complex. Proc Natl Acad Sci 107: 22399-22406.

Schiavo G, Benfenati F, Poulain B, Rossetto O, Polverino de Laureto P, DasGupta BR, Montecucco C. 1992. Tetanus and botulinum-B neurotoxins block neurotransmitter release by proteolytic cleavage of synaptobrevin. Nature 359: $832-835$.

Schmitz F, Königstorfer A, Südhof TC. 2000. RIBEYE, a component of synaptic ribbons: A protein's journey through evolution provides insight into how synaptic ribbons function. Neuron 28: 857-872.

Schoch S, Castillo PE, Jo T, Mukherjee K, Geppert M, Wang Y, Schmitz F, Malenka RC, Südhof TC. 2002. RIM1a forms a protein scaffold for regulating neurotransmitter release at the active zone. Nature 415: 321-326.

Sharma M, Burré J, Südhof TC. 2011. CSP $\alpha$ promotes SNARE-complex assembly by chaperoning SNAP-25 during synaptic activity. Nature Cell Biol 13: 30-39.

Shen J, Tareste DC, Paumet F, Rothman JE, Melia TJ. 2007. Selective activation of cognate SNAREpins by Sec1/ Munc18 proteins. Cell 128: 183-195.

Shin O-H, Lu J, Rhee J-S, Tomchick DR, Pang ZP, Wojcik S, Camacho-Perez M, Brose N, Machius M, Rizo J, Rosenmund C, Südhof TC. 2010. Munc13 C $\mathrm{C}_{2}$ B-domain - an activity-dependent $\mathrm{Ca}^{2+}$-regulator of synaptic exocytosis. Nature Struct Mol Biol 17: 280-288.

Simon SM, Llinás RR. 1985. Compartmentalization of the submembrane calcium activity during calcium influx and its significance in transmitter release. Biophys J 48: 485-498.

Söllner T, Bennett MK, Whiteheart SW, Scheller RH, Rothman JE. 1993. A protein assembly-disassembly pathway in vitro that may correspond to sequential steps of synaptic vesicle docking, activation, and fusion. Cell 75: 409-418.

Südhof TC. 2004. The synaptic vesicle cycle. Annu Rev Neurosci 27: 509-547. 
T.C. Südhof and J. Rizo

Südhof TC, Rothman JE. 2009. Membrane fusion: Grappling with SNARE and SM proteins. Science 323: 474477.

Sutton RB, Fasshauer D, Jahn R, Brunger AT. 1998. Crystal structure of a SNARE complex involved in synaptic exocytosis at $2.4 \AA$ resolution. Nature 395: 347-353.

Takamori S, Holt M, Stenius K, Lemke EA, Grønborg M, Riedel D, Urlaub H, Schenck S, Brügger B, Ringler P, et al. 2006. Molecular anatomy of a trafficking organelle. Cell 127: 831-846.

Tobaben S, Thakur P, Fernandez-Chacon R, Rettig J, Südhof TC, Stahl B. 2001. A trimeric protein complex functions as a synaptic chaperone machine. Neuron 31: 987-999.

tom Dieck S, Sanmartí-Vila L, Langnaese K, Richter K, Kindler S, Soyke A, Wex H, Smalla KH, Kämpf U, Fränzer JT. 1998. Bassoon, a novel zinc-finger CAG/glutaminerepeat protein selectively localized at the active zone of presynaptic nerve terminals. J Cell Biol 142: 499-509.

van den Bogaart G, Holt MG, Bunt G, Riedel D, Wouters FS, Jahn R. 2010. One SNARE complex is sufficient for membrane fusion. Nat Struct Mol Biol 17: 358-364.

Verhage M, Maia AS, Plomp JJ, Brussaard AB, Heeroma JH, Vermeer H, Toonen RF, Hammer RE, van den Berg TK, Missler M, et al. 2000. Synaptic assembly of the brain in the absence of neurotransmitter secretion. Science 287: 864-869.

Wang Y, Okamoto M, Schmitz F, Hofman K, Südhof TC. 1997. RIM: A putative Rab3-effector in regulating synaptic vesicle fusion. Nature 388: 593-598.

Wang X, Kibschull M, Laue MM, Lichte B, Petrasch-Parwez E, Kilimann MW. 1999. Aczonin, a 550-kD putative scaffolding protein of presynaptic active zones, shares homology regions with Rim and Bassoon and binds profilin. J Cell Biol 147: 151-162.

Wang Y, Sugita S, Südhof TC. 2000. The RIM/NIM family of neuronal SH3-domain proteins: Interactions with Rab3 and a new class of neuronal SH3-domain proteins. $J$ Biol Chem 275: 20033-20044.

Wang Y, Liu X, Biederer T, Südhof TC. 2002. A family of RIM-binding proteins regulated by alternative splicing: Implications for the genesis of synaptic active zones. Proc Natl Acad Sci 99: 14464-14469.

Weber T, Zemelman BV, McNew JA, Westermann B, Gmachl M, Parlati F, Söllner TH, Rothman JE. 1998. SNAREpins: Minimal machinery for membrane fusion. Cell 92: 759-772.

Wilson DW, Wilcox CA, Flynn GC, Chen E, Kuang WJ, Henzel WJ, Block MR, Ullrich A, Rothman JE. 1989. A fusion protein required for vesicle-mediated transport in both mammalian cells and yeast. Nature 339: 355-359.

Wu MN, Schulze KL, Lloyd TE, Bellen HJ. 2001. The ROPsyntaxin interaction inhibits neurotransmitter release. Eur J Cell Biol 80: 196-199.

Yamaguchi T, Dulubova I, Min SW, Chen X, Rizo J, Südhof TC. 2002. Sly1 binds to Golgi and ER syntaxins via a conserved N-terminal peptide motif. Developmental Cell 2: 295-305.

Yang B, Gonzalez LJr, Prekeris R, Steegmaier M, Advani RJ, Scheller RH. 1999. SNARE interactions are not selective. Implications for membrane fusion specificity. J Biol Chem 274: 5649-5653.

Zhen M, Jin Y. 1999. The liprin protein SYD-2 regulates the differentiation of presynaptic termini in $C$. elegans. Nature 401: 371-375. 


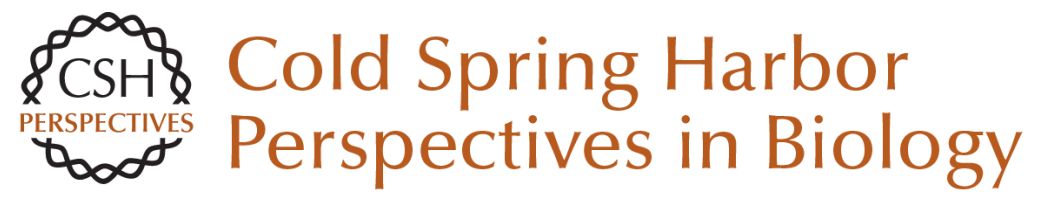

\section{Synaptic Vesicle Exocytosis}

Thomas C. Südhof and Josep Rizo

Cold Spring Harb Perspect Biol 2011; doi: 10.1101/cshperspect.a005637 originally published online October 25, 2011

\section{Subject Collection The Synapse}

Studying Signal Transduction in Single Dendritic Spines Ryohei Yasuda

Synaptic Vesicle Pools and Dynamics AbdulRasheed A. Alabi and Richard W. Tsien

Synapses and Memory Storage Mark Mayford, Steven A. Siegelbaum and Eric $R$. Kandel

Synapses and Alzheimer's Disease Morgan Sheng, Bernardo L. Sabatini and Thomas C. Südhof

\section{Synaptic Cell Adhesion}

Markus Missler, Thomas C. Südhof and Thomas Biederer

Synaptic Dysfunction in Neurodevelopmental Disorders Associated with Autism and Intellectual Disabilities

Huda Y. Zoghbi and Mark F. Bear

The Postsynaptic Organization of Synapses Morgan Sheng and Eunjoon Kim

Presynaptic LTP and LTD of Excitatory and Inhibitory Synapses

Pablo E. Castillo
Synaptic Vesicle Endocytosis

Yasunori Saheki and Pietro De Camilli

Short-Term Presynaptic Plasticity Wade G. Regehr

NMDA Receptor-Dependent Long-Term

Potentiation and Long-Term Depression

(LTP/LTD) Christian Lüscher and Robert C. Malenka

Ultrastructure of Synapses in the Mammalian

Brain Kristen M. Harris and Richard J. Weinberg

Calcium Signaling in Dendritic Spines Michael J. Higley and Bernardo L. Sabatini

Synaptic Neurotransmitter-Gated Receptors Trevor G. Smart and Pierre Paoletti

Synaptic Vesicle Exocytosis

Thomas C. Südhof and Josep Rizo

Vesicular and Plasma Membrane Transporters for Neurotransmitters

Randy D. Blakely and Robert H. Edwards

For additional articles in this collection, see http://cshperspectives.cshlp.org/cgi/collection/

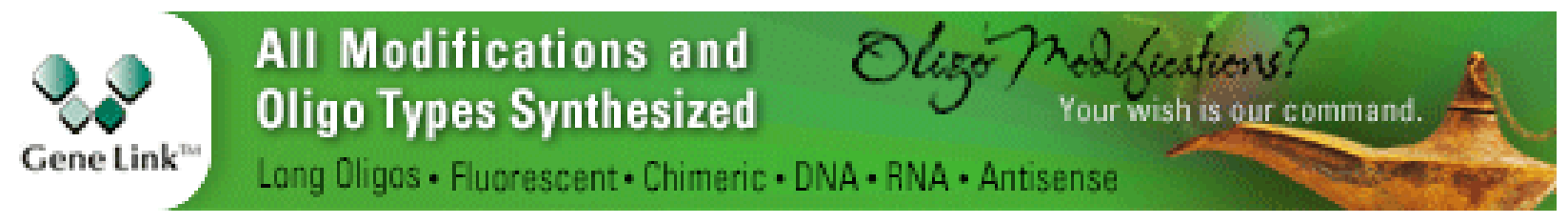

